\title{
PENGEMBANGAN SISTEM INFORMASI PENGOLAHAN STOK BARANG TOKO DUAL COMM TANJUNGPINANG BERBASIS CLIENT SERVER
}

\author{
Andrew ${ }^{1}$, Hendi Setiawan ${ }^{2}$ \\ ${ }^{1,2}$ Jurusan Sistem Informasi STT Indonesia Tanjungpinang \\ ${ }^{1,2}$ Jln. Pompa Air No. 28 Tanjungpinang Kepulauan Riau Indonesia \\ 1dermaven101@gmail.com \\ ${ }^{2}$ hendisetiawan016@gmail.com
}

\begin{abstract}
Intisari - Pengolahan stok barang di Toko Dual Comm saat ini dalam pengolahan data barang masuk dan keluar meliputi barang pembelian atau penambahan stok barang dan juga untuk keluar sebagai penjualan. Agar proses pengolahan data barang masuk dan keluar dapat berjalan dengan efektif dan efisien, maka sudah seharusnya untuk menggunakan aplikasi sistem informasi pengolahan data barang masuk dan keluar yang dapat menangani proses barang masuk dan keluar. Dengan dibentuknya suatu sistem dengan proses terkomputerisasi berbasis client server, maka diharapkan dapat mengatasi masalah-masalah yang telah terjadi. Dalam melakukan penelitian ini, metode pengembangan perangkat lunak yang digunakanadalah metode waterfall yang terdiri dari rekayasa sistem, analisis, desain, implementasi, pengujian dan pemeliharaan. Aplikasi ini dibangun dengan Bahasa pemograman Netbeans dan PhpMyAdmin. Hasil dari penelitian ini adalah sistem perangkat lunak yang berbasis client server untuk proses pengolahan data barang masuk dan keluar. Dengan adanya aplikasi ini diharapkan untuk mempermudah dan mempercepat kinerja pihak Toko Dual Comm terutama dibagian accounting dalam proses barang masuk dan keluar.

Kata Kunci : Sistem informasi, Penjualan dan stok barang, Bahasa pemograman Netbeans dan PhpMyAdmin, accounting.
\end{abstract}

Abstract - Processing sales and stock of goods in Dual Comm is still using manual system, in the processing of data entry and exit goods include goods purchases or additional stock of goods and also to come out as a sales. In order to process data processing incoming and outgoing goods can run effectively and efficiently, then it is supposed to use the application information system data processing incoming and outgoing goods that can handle the process of goods in and out. With the establishment of a system with a computerized with client server process, it is expected to overcome the problems that have occurred. In doing this research, software development method used is waterfall method which consists of system engineering, analysis, design, implementation, testing and maintenance. This application is built with programming languages Netbeans and PhpMyAdmin. The result of this research is software system with client server for data processing process of incoming and outgoing goods. With this application is expected to simplify and fasten the Dual Comm especially in the accounting section in the process of goods in and out. Keywords: Information system, Sales and stock of goods, Netbeans programming language and PhpMyAdmin, accounting.

\section{Pendahuluan}

Dalam perusahaan, pemanfaatan dan penggunaan teknologi informasi diantaranya sistem pengarsipan data sangat penting untuk menunjang perkembangan perusahaan. Hal ini dikarenakan dengan adanya suatu sistem pengarsipan data pada suatu perusahaan maka dapat mempercepat suatu proses kerja dan dapat memudahkan dalam penyusunan data stok barang serta menjadikan pengolahan data yang lebih teratur sesuai kategori data yang tersimpan.

Toko Dual Comm Tanjungpinang ini bergerak di bidang penjualan barang komputer dan telepon genggam, dalam proses pencatatan baik pencatatan penjualan kepada konsumen dan pencatatan stok barang yang ada di gudang sudah dilakukan secara komputerisasi, tetapi karena banyaknya inputan penjualan yang harus dilakukan, sehingga dalam kondisi jangka panjang terdapat kesulitan yang kurang cepat pada satu komputer untuk melakukan laporan seperti laporan penjualan, pembelian dan stok barang.
Mengingat begitu pentingnya faktor data, informasi serta sistem bagi perusahaan, sehingga berhasil tidaknya perusahaan dalam menjalankan fungsinya tergantung dari ketiga hal diatas. Berdasarkan kenyataan tersebut di atas, maka penulis merasa perlu untuk melakukan perancangan pengolahan data barang yang dapat digunakan oleh lebih dari satu komputer untuk bekerja secara efektivitivitas dan efisiensi dalam pembuatan laporan penjualan dan laporan stok barang. Semua proses yang berhubungan dengan data penjualan dan stok dapat dialihkan ke sistem komputer yang berbasis client server. Client server merupakan jaringan yang didesain untuk pengguna, yaitu pengguna tersebut disebut dengan client, untuk mengakses sumber daya seperti lagu, koleksi video, atau beberapa layanan lainnya dari komputer pusat yang disebut server. Jaringan client server merupakan dimana satu komputer terpusat (server) adalah pusat dimana banyak komputer pribadi atau workstation yang sangat kuat (disebut client) terhubung. Client menjalankan aplikasi dan mengakses data yang tersimpan dalam server. 


\section{Metodologi Penelitian}

\section{a. Metode Pengumpulan Data}

Metode ini dilakukan dengan cara meneliti kebutuhan yang diperlukan, apa saja kesulitan yang biasa terjadi pada saat penginputan data. Karena adanya sistem yang sudah berjalan pada perusahaan tersebut, maka diperlukan pengembangan sistem yang sudah ada menjadi sebuah sistem yang final.

\section{b. Metode Pengembangan Perangkat Lunak}

Metode pengembangan sistem yang digunakan adalah Model Prototype, yang merupakan suatu proses pembuatan aplikasi yang bersifat berulang dan dengan perencanaan yang cepat dimana terdapat umpan balik yang memungkinkan terjadinya perulangan dan perbaikan aplikasi sampai aplikasi tersebut memenuhi kebutuhan dari pengguna.

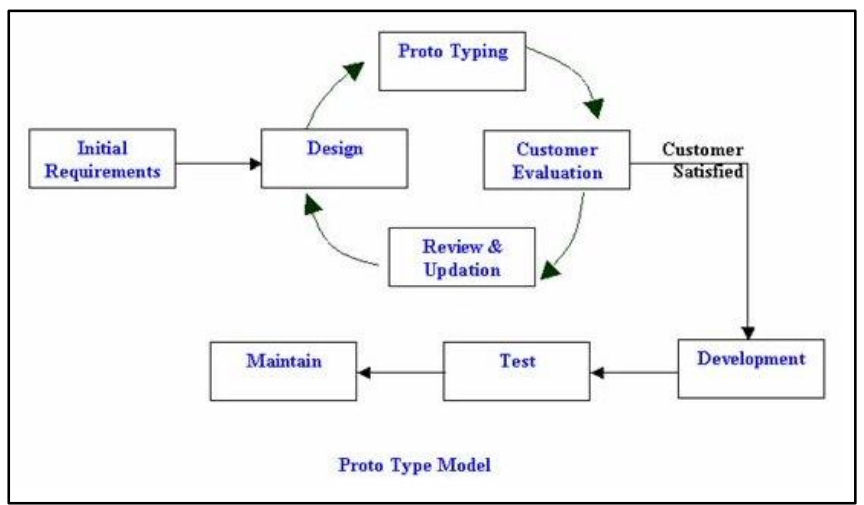

Gambar 1. Metode prototype

\section{HASIL DAN PEMBAHASAN}

\section{a. Analisis Sistem}

Berikut adalah hasil analisis sistem yang berjalan di Toko Dual Comm Tanjungpinang :

1. Berikut adalah penjelasan dan gambar flowmap pembelian barang yang berjalan di Toko Dual Comm Tanjungpinang :

a. Pada prosedur pembelian barang masih sama seperti sebelumya, admin mengecek stok barang yang kurang, kemudian membuat daftar barang pemesanan dan memberikan daftar pemesanan kepada pihak supplier. Pihak supplier menyiapkan barang yang dipesan, kemudian membuat nota pemesanan barang dan menyerahkan kepada Admin.

b. Admin mengecek daftar pesanan apakah cocok dengan pesanan yang diminta. Jika tidak cocok, maka admin menyerahkan kembali daftar pesanan yang kurang dan menerima barang yang tersedia. Jika cocok, admin membuat laporan pembelian barang kemudian diinput ke dalam database, dan melakukan pembayaran pembelian barang dengan uang yang diterima dari pemilik toko.
Untuk lebih jelasnya prosedur saat pembelian barang terjadi, dapat dilihat pada gambar flowmap berikut ini :

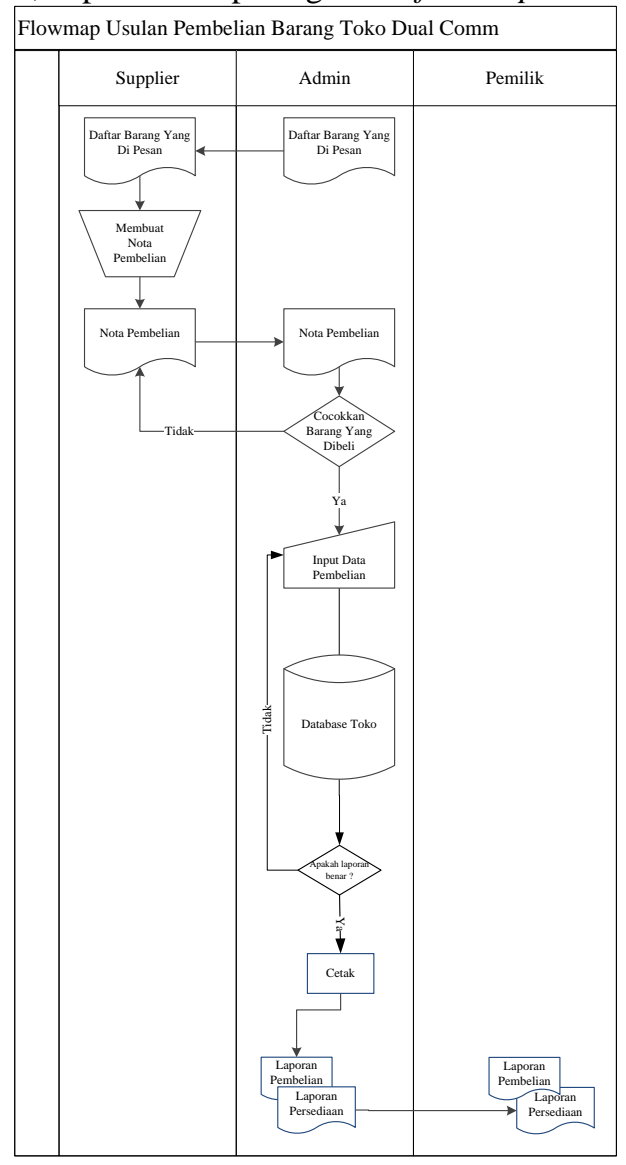

Gambar 2. Flowmap Berjalan Pembelian Barang

2. Berikut adalah penjelasan dan gambar flowmap penjualan barang yang berjalan di Toko Dual Comm Tanjungpinang :

a. Pada prosedur penjualan, Admin dapat mengakses penuh sebagai kasir, dimana admin atau kasir menawarkan produk kepada konsumen, kemudian konsumen memilih produk yang ingin dibeli. Jika produk yang ditawarkan sesuai keinginan konsumen, maka konsumen memberikan daftar barang yang diinginkan.

b. Pihak admin atau kasir menerima daftar barang yang dibeli konsumen, kemudian mengecek apakah stok tersebut tersedia, jika ada maka data akan diinput ke database. Jika tidak tersedia, pihak admin atau kasir memberi tahu kepada konsumen bahwa barang tersebut tidak tersedia.

c. Pihak admin atau kasir mencetak struk barang kemudian menyerahkan kepada konsumen dan admin atau kasir menerima uang penjualan barang.

d. Pada saat penutupan toko, pihak admin mencetak laporan penjualan dan menyerahkan laporan penjualan serta uang penjualan barang pada hari tersebut.

Untuk lebih jelasnya prosedur saat penjualan barang terjadi, dapat dilihat pada gambar flowmap berikut ini : 


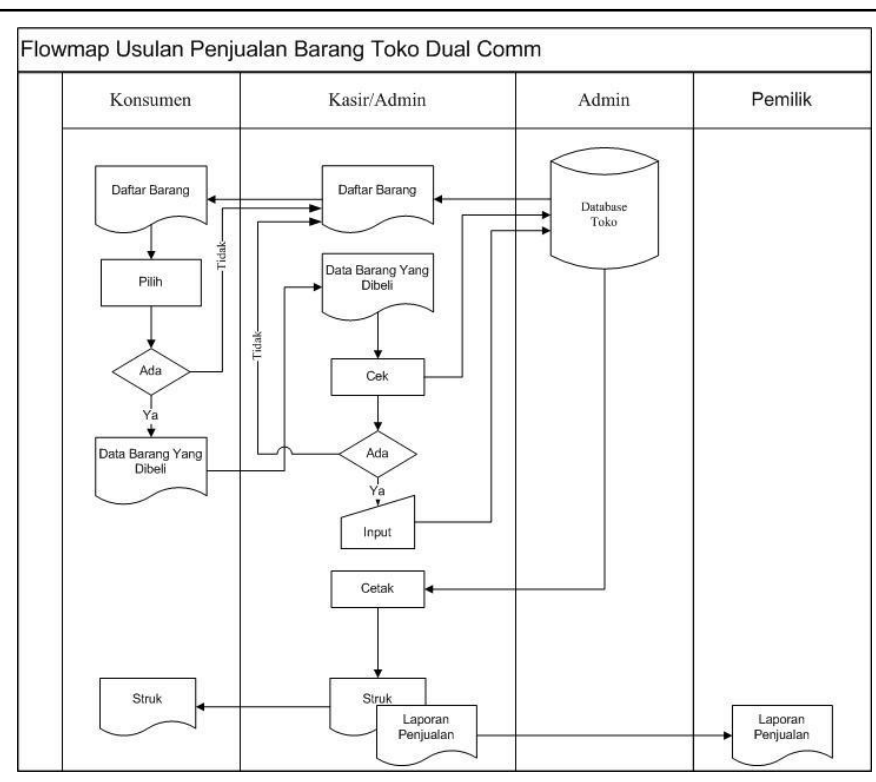

Gambar 3 Flowmap Berjalan Penjualan Barang

\section{b. Perancangan Prosedur}

\section{Analisa Kebutuhan Data}

Aplikasi pembelian dan penjualan barang berbasis client server membutuhkan data barang untuk diproses dan akan menghasilkan laporan stok dan penjualan pembelian.

\section{Analisa Kebutuhan Fungsional}

Kebutuhan fungsional adalah jenis kebutuhan yang berisi proses-proses apa saja yang nantinya dilakukan oleh sistem. Kebutuhan fungsional juga berisi informasi-informasi apa saja yang harus ada dan dihasilkan oleh sistem. Berikut adalah kebutuhan fungsional yang dimiliki oleh aplikasi yang akan dibuat ini :

1. Sistem harus dapat melakukan input nama barang baru pada menu barang

2. Sistem harus dapat melakukan input pembelian barang dan penjualan barang.

3. Sistem harus dapat menampilkan hasil inputan dari pihak server maupun client.

4. Sistem harus dapat mengolah inputan client server menjadi sebuah laporan.

\section{Analisa Kebutuhan Non-Fungsional}

Kebutuhan non-fungsional adalah tipe kebutuhan yang berisi properti prilaku yang dimiliki oleh sistem, meliputi : operasional, kinerja, keamanan dan informasi. Berikut adalah kebutuhan fungsional yang dimiliki oleh aplikasi yang akan dibuat ini :

1. Operasional

a. Digunakan pada sistem operasi Windows 8.1

b. Kebutuhan memori RAM 1 GB

2. Informasi

a. Digunakan untuk menampilkan data stok barang beli dan jual

b. Digunakan untuk memberikan informasi stok barang seperti nama barang dan harga.

\section{Analisa Kelemahan Sistem}

Analisis kelemahan sistem dalam penelitian ini dimaksudkan untuk mengidentifikasi dan mengevaluasi permasalahan, hambatan yang terjadi, serta kebutuhan-kebutuhan yang diharakan sehingga dapat diusulkan perbaikan.

Pada tahap ini harus mengenal permasalahan yang dihadapi sistem lama pada Toko Dual Comm Tanjungpinang terutama pada transaksi penjualan barang. Adapun permasalahan yang dihadapi oleh Toko Dual Comm Tanjungpinang adalah:

1. Proses transaksi ketika banyak menjadi kacau karena sistem yang digunakan hanya satu komputer, sehingga pelanggan harus menunggu lama dalam sebuah transaksi.

2. Sistem yang sebelumnya digunakan pada perusahaan ini masih belum banyak fitur seperti potongan harga maupun sistem retur maka pihak toko mendapatkan kesulitan dalam pengolahan stok barang.

\section{Analisa Kebutuhan Sistem}

Pada analisis kebutuhan sistem bersangkutan pembahasan pada kebutuhan informasi dan kebutuhan pengguna :

1. Kebutuhan Perangkan Lunak

Kebutuhan perangkat lunak yang digunakan adalah operasi sistem Windows 8.1, Netbeans, MySQL, PHPMyAdmin, Microsoft Visio, dan iReport.

2. Kebutuhan Informasi

Pengguna membutuhkan aplikasi yang bisa melakukan transaksi penjualan dan pembelian barang secara cepat dan akurat.

3. Kebutuhan Pengguna

Aplikasi ini dirancang khusus untuk digunakan dalam pengolahan stok barang berbasis client server pada Toko Dual Comm Tanjungpinang.

6. Analisis PIECES (Performance, Information, Economy, Control, Efficiency, dan Servcice)

Pada tulisan ini, penulis melaukan analisis terhadap kinerja, informasi, ekonomi, kendali, efisiensi dan pelayanan. Panduan ini dikenal dengan alalisis PIECES (Performance, Information, Economy, Control, Efficiency, dan Servcice).

1. Analisis Kinerja (Performace)

Kinerja merupakan bagian dalam kelancaran proses kerja dalam suatu organisasi. Masalah kerja dapat terjadi dalam suatu organisasi ketika tugas operasional dijalankan terlalu lambat dalam mencapai sasaran yang diinginkan dan cenderung menurun. 
Tabel 1 Analisis Kinerja

\begin{tabular}{|c|c|c|c|}
\hline No & Faktor & Sistem Lama & Sistem Baru \\
\hline 1 & Throughtput & $\begin{array}{c}\text { Penjualan hanya } \\
\text { dilakukan oleh } \text { admin }\end{array}$ & $\begin{array}{c}\text { Penjualan dapat dilakukan } \\
\text { oleh } \text { admin dan kasir }\end{array}$ \\
\hline 2 & Response Time & $\begin{array}{c}\text { Harus menunggu } \\
\text { transaksi sebelumnya } \\
\text { selesai }\end{array}$ & $\begin{array}{c}\text { Dapat langsung transaksi } \\
\text { pada komputer lain tanpa } \\
\text { menunggu }\end{array}$ \\
\hline
\end{tabular}

2. Analisis Informasi (Information)

Dalam penyampaian informasi sering terjadi keterlambatan, bahkan kesalahan informasi. Oleh sebab itu diharapkan adanya informasi yang akurat, tepat waktu dan relevan (sesuai dengan yang dibutuhkan).

Tabel 2 Analisis Informasi (Information)

\begin{tabular}{|c|c|c|c|}
\hline No & Faktor & Sistem Lama & Sistem Baru \\
\hline 1 & Akurat & $\begin{array}{c}\text { Informasi data yang } \\
\text { diberikan kurang } \\
\text { akurat }\end{array}$ & $\begin{array}{c}\text { Informasi yang data } \\
\text { berhubungan antara } \text { client } \\
\text { dan server }\end{array}$ \\
\hline 2 & Relevan & $\begin{array}{c}\text { Informasi yang } \\
\text { diberikan kepada } \\
\text { pelanggan kurang } \\
\text { lengkap }\end{array}$ & $\begin{array}{c}\text { Informasi yang diberikan } \\
\text { kepada pelanggan lengkap } \\
\text { seperti potongan harga } \\
\text { dan informasi barang }\end{array}$ \\
\hline 3 & Tepat Waktu & $\begin{array}{c}\text { Membutuhkan waktu } \\
\text { lama dalam transaksi } \\
\text { karena harus } \\
\text { menunggu transaksi } \\
\text { sebelumnya selesai }\end{array}$ & $\begin{array}{c}\text { Waktu yang dibutuhkan } \\
\text { pelanggan lebih singkat } \\
\text { untuk melakukan transaksi }\end{array}$ \\
\hline
\end{tabular}

3. Analisis Ekonomi (Economy)

Analisis ekonomi adalah penilaian sistem atas pengurangan dan keuntungan yang akan didapatkan dari sistem yang dikembangkan. Sistem ini akan memperhemat biaya operasional dan meningkatkan keuntungan perusahaan.

Tabel 3 Analisis Ekonomi (Economy)

\begin{tabular}{|c|c|c|c|}
\hline No & Faktor & Sistem Lama & Sistem Baru \\
\hline 1 & Biaya & $\begin{array}{c}\text { Tidak memerlukan } \\
\text { jaringan internet }\end{array}$ & $\begin{array}{c}\text { Memerlukan jaringan } \\
\text { internet agar } \text { client dan } \\
\text { server dapat terhubung }\end{array}$ \\
\hline
\end{tabular}

4. Analsis Pengendalian (Control)

Kinerja merupakan bagian dalam kelancaran proses kerja dalam suatu organisasi. Masalah kerja dapat terjadi dalam suatu organisasi ketika tugas operasional dijalankan terlalu lambat dalam mencapai sasaran diinginkan dan cenderung menurun.
Tabel 4 Analisis Pengendalian

\begin{tabular}{|c|c|c|c|}
\hline No & Faktor & Sistem Lama & Sistem Baru \\
\hline 1 & $\begin{array}{c}\text { Pengendalian } \\
\text { Informasi }\end{array}$ & $\begin{array}{c}\text { Banyak transaksi } \\
\text { menjadi menumpuk }\end{array}$ & $\begin{array}{c}\text { Banyak transaksi dapat } \\
\text { dibagi } 2 \text { atau lebih } \\
\text { komputer }\end{array}$ \\
\hline
\end{tabular}

5. Analisis Efisiensi (Efficiency)

Analisis efisiensi adalah peningkatan terhadap efisiensi operasional, berada dengan ekonomi. Bila ekonomi berhubungan dengan inputnya, efisiensi tersebut berhubungan dengan bagaimana sumber daya itu digunakan agar tidak terjadi pemborosa. Sistem dikatakan efisien atau berhasil, jika dapat mencapai sasaran yang diinginkan, tidak mengeluarkan banyak waktu dan tenaga kerja yang berlebihan.

Tabel 5 Analisis Efisiensi (Efficiency)

\begin{tabular}{|c|c|c|c|}
\hline No & Faktor & Sistem Lama & Sistem Baru \\
\hline \multirow{2}{*}{1} & $\begin{array}{c}\text { Jumlah Sumber } \\
\text { Daya }\end{array}$ & $\begin{array}{c}\text { Dapat digunakan satu } \\
\text { komputer }\end{array}$ & $\begin{array}{c}\text { Dapat digunakan banyak } \\
\text { komputer }\end{array}$ \\
\hline
\end{tabular}

6. Analisis Layanan (Services)

Analisis pelayanan adalah peningkatan terhadap layanan yang dihasilkan oleh sistem yang diterapkan untuk menyelesaikan pekerjaan, kemudahan untuk memperoleh data-data yang dibutuhkan untuk proses evaluasi kerja serta kemudahan bagi pelanggan mendapatkan informasi.

Tabel 6 Analisis Layanan (Services)

\begin{tabular}{|c|c|c|c|}
\hline No & Faktor & Sistem Lama & Sistem Baru \\
\hline \multirow{4}{*}{1} & Prosedur Untuk & Pelanggan melakukan & Pelanggan dapat \\
& Mndapatkan & transaksi pada satu & melakukan transaksi pada \\
& Informasi & komputer & komputer yang tersedia \\
\hline
\end{tabular}

\section{c. Implementasi Antarmuka (Interface)}

\section{Implementasi Halaman Login}

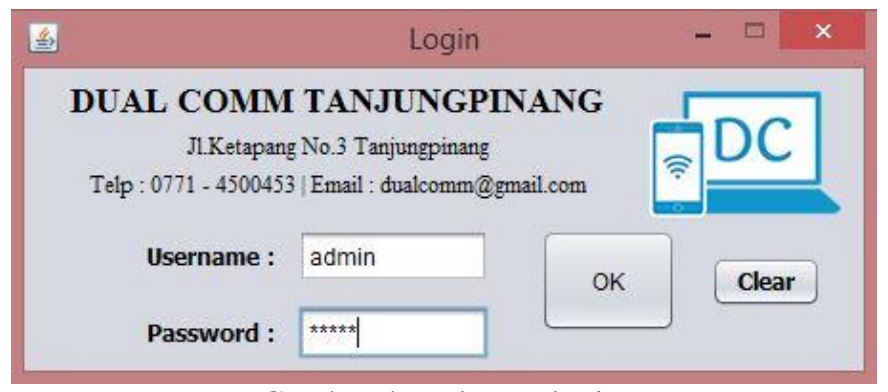

Gambar 4. Halaman login

Halaman Login merupakan halaman paling awal pada aplikasi yang berfungsi untuk verifikasi identitas pengguna yang telah terdaftar pada sistem. Jika identitas yang dimasukkan benar, maka akan dilanjutkan ke menu utama aplikasi. 


\section{Implementasi Halaman Beranda}

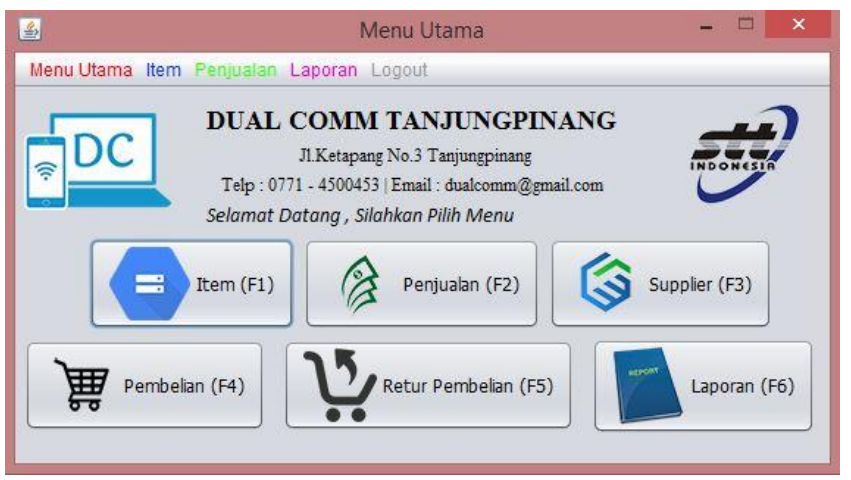

Gambar 5. Halaman beranda

Halaman Beranda merupakan menu dimana pengguna dapat memilih apa saja yang ingin digunakan pada aplikasi tersebut. Fitur-fitur tersebut dapat ditekan dengan quick shortcut atau tombol cepat agar pengguna dapat memilih tanpa menggunakan mouse seperti tombol F1, F2, dan sebagainya.

\section{Implementasi Halaman Item}

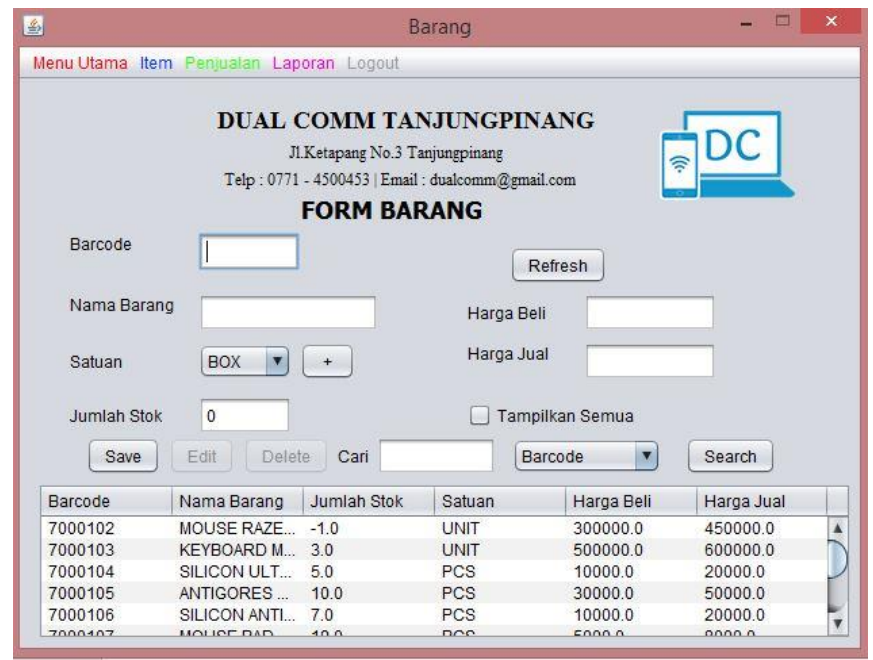

Gambar 6. Halaman item

Halaman Item atau halaman barang merupakan halaman tampilan informasi barang yang didaftar ke dalam sistem, seperti harga beli, harga jual, jumlah stok, barcode, satuan, dan nama barang.

\section{Implementasi Halaman Penjualan}

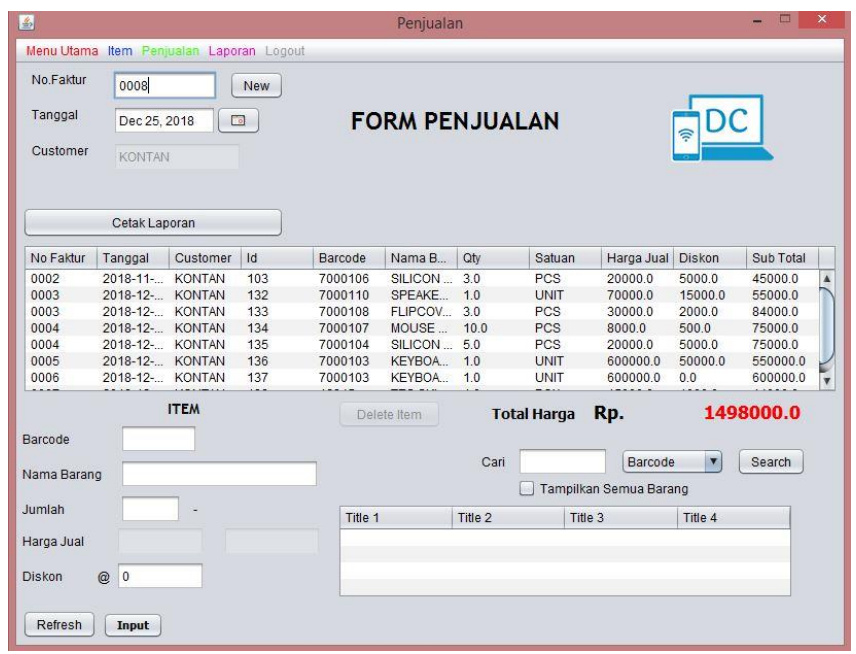

Gambar 7. Halaman penjualan

Halaman Penjualan merupakan halaman terjadinya sebuah transaksi antara pihak toko dengan pelanggan, yang berisi tentang informasi jumlah barang yang dibeli dan total harga pembelian.

\section{Implementasi Halaman Pembelian}

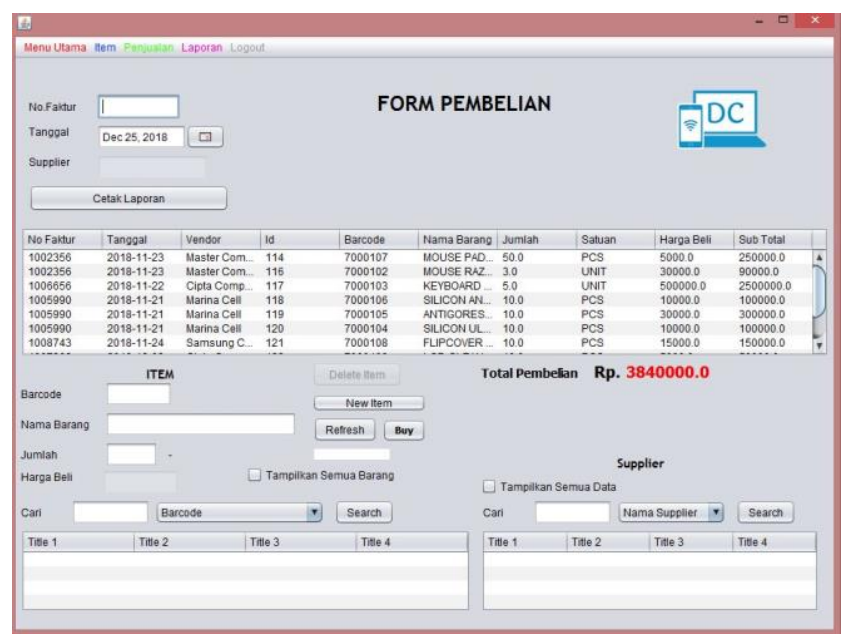

Gambar 8. Halaman pembelian

Halaman Pembelian merupakan halaman terjadinya sebuah transaksi antara pihak toko dengan supplier, yang berisi tentang informasi jumlah barang yang dibeli dan total harga pembelian. 


\section{Implementasi Halaman Supplier}

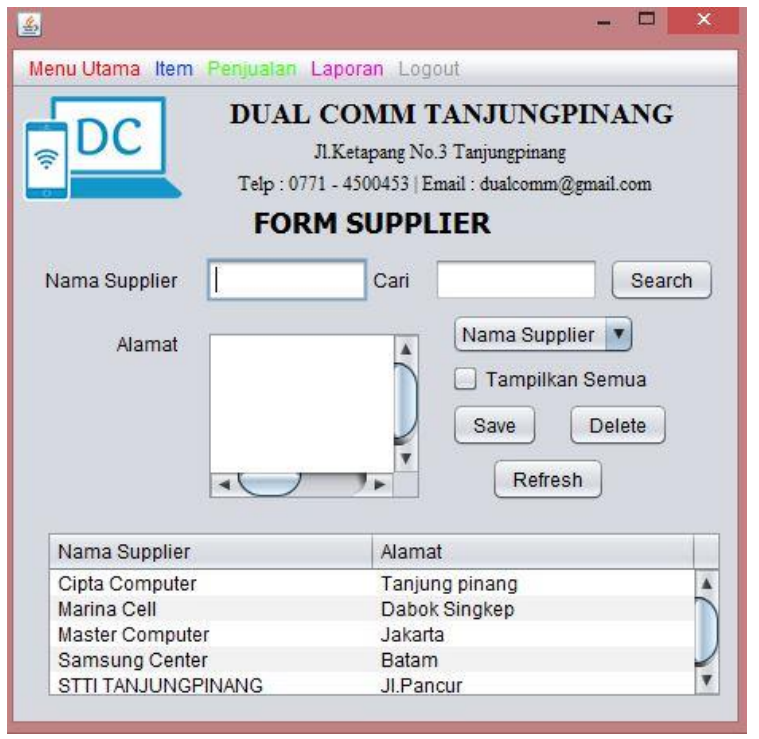

Gambar 9. Halaman supplier

Halaman Supplier merupakan halaman tampilan informasi supplier yang didaftar ke dalam sistem, seperti nama supplier dan alamat.

\section{Implementasi Halaman Retur Pembelian}

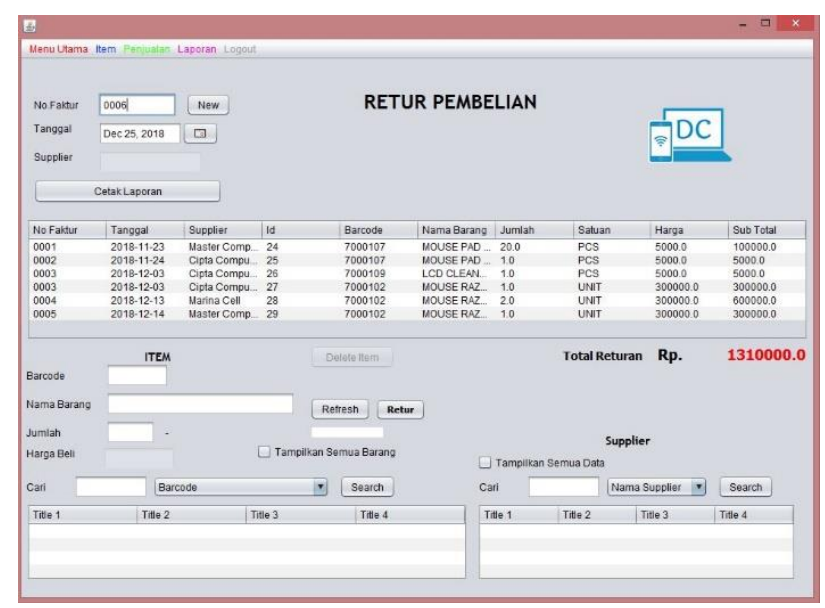

Gambar 10. Halaman retur pembelian

Halaman Retur Pembelian merupakan halaman terjadinya sebuah transaksi antara pihak toko dengan supplier, yang berisi tentang informasi jumlah barang yang diretur dan total harga returan.
8. Implementasi Halaman Laporan

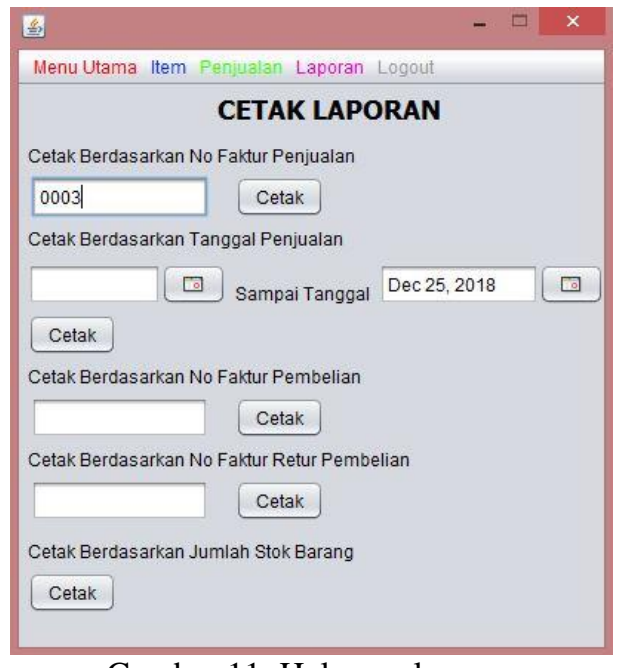

Gambar 11. Halaman laporan

Halaman Laporan merupakan halaman tampilan untuk menentukan tanggal atau nomor faktur sesuai yang ingin dicetak.

\section{Implementasi Halaman Nota}

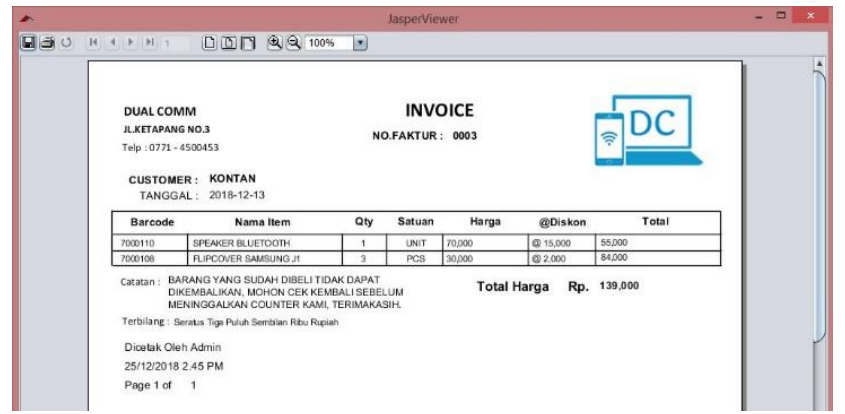

Gambar 12. Halaman nota

Halaman Nota merupakan halaman tampilan untuk hasil inputan informasi penjualan atau pembelian yang akan dicetak.

\section{d. Pengujian}

Pengujian perangkat lunak adalah proses untuk mencari kesalahan pada setiap item perangkat lunak, mencatat hasilnya, mengevaluasi setiap aspek pada setiap komponen sistem dan mengevaluasi semua fasilitas dari perangkat lunak yang dikembangkan.

Pengujian merupakan bagian yang penting dalam siklus pembangunan perangkat lunk. Tujuan dari pengujian adalah untuk menjamin perangkat lunak yang dibangun memiliki kualitas yang handal, yaitu mampu mempresentasikan kajian pokok dari spesifikasi, analisis, perancangan dan pengkodean dari perangkat lunak itu sendiri.

Pengujian perangkat lunak Pengembangan Sistem Informasi pengolahan stok barang ini menggunakan metode prototype, sehingga sitem informasi yang dikembangkan akan menjadi lebih baik.

Berdasarkan pengujian yang telah dilakukan dpat disimpulkan bahwa sistem yang dikembangkan bebas dari 
kesalahan fatal dan dapat mengeluarkan hasil sesuai yang diharapkan.

\section{KESIMPULAN}

Setelah merancang dan membangun sistem informasi pengolahan stok barang berbasis client server, penulis dapat menyimpulkan bahwa :

1. Perancangan aplikasi sistem informasi pengolahan stok barang berbasis client server dapat membantu dalam penyusunan laporan yang tepat dan akurat, sehingga dapat memberikan informasi yang lebih cepat dan efisien.

2. Pengolahan data antara client dan server selalu terhubung dalam mencari data dan melihat data sehingga dapat meningkatkan keakuratan pekerja.

Pelayanan terhadap konsumen menjadi lebih cepat dan efektif karena data bisa dicari lebih dari satu komputer dengan waktu yang sangat singkat.

Adapun saran yang dapat diberikan untuk penyempurnaan dari sistem ini adalah:

Dari hasil pengamatan penulis dengan melakukan penelitian, perancangan hingga pembuatan perangkat lunak untuk sistem informasi pengolahan stok barang berbasis client server, terdapat beberapa saran, diantaranya :

1. Dapat mengimplementasikan program ke dalam sistem operasi android

2. Dapat membuat brosur atau katalog barang yang lebih menarik secara digital untuk mendapatkan peminat yang lebih banyak. Dapat menambahkan lebih banyak fitur kepada program yang sudah ada

3. Dapat menstabilkan program yang lebih ringan agar dapat digunakan pada komputer yang memiliki spesifikasi rendah.

4. Dapat mengembangkan program dengan menggunakan bahasa pemrograman yang lain.

\section{REFERENSI}

[1] Hartati Putra, S., Sistem Pendukung Keputusan Berbasis Client Server Untuk Penentuan Biaya Pembangunan Rumah, Vol.4 Nomor 1, Hal 39, 2001, Jurnal Ilmu Komputer, Bandung.

[2] ShourtCouse, Pengembangan Aplikasi Database Berbasis JavaDB dengan Netbeans, Hal 2,2010, Andi Offset, Yogyakarta.

[3] Cahyo Untoro Meida, 10 November 2016, Model Prototype, Online pada http://share.its.ac.id/metodeprototype.html, diakses 19 Desember 2018, 14.44 WIB

[4] Nurzaman Alvin, 11 Februari 2018, Pengertian dan Sejarah Microsoft Visio, Online pada http://www.sahabatie.com/2018/02/pengertian-dansejarah-microsoft-visio.html, diakses 28 November 2018, 20:55 WIB

[5] Dahlan Niko Bayu, 25 Juli 2016, Mengenal dan Memulai Pemrograman Java, Online pada https://www.codepolitan.com/mengenal-danmemulai-pemrograman-java-belajar-java, diakses 18 September 2018 , 17:40 WIB.

[6] Ashar Fajar, 2010, Pengertian Data dan Jenis Data, Online pada http://pengertianahli.id/2013/11/pengertian-data-dan-jenis-data-2.html, diakses 18 September 2018, 14:45 WIB.

[7] Indyawan Faras, 21 Agustus 2018, Virtual Box, Online pada http://www.kitaadmin.com/2018/08/virtualbox-adalah-pengertianfungsi

[8] Makhdoum, 3 November 2017, Pengertian Client Server, Online pada https://www.dictio.id/t/apa-yang-dimaksud-dengan-jaringan-clientserver-dan-apa-contohnya/13882/3, di akses 28 November 2018, 20.24 WIB.

[9] Zakaria Muhammad, 7 Agustus 2016, Sejarah Windows, Online pada https://www.nesabamedia.com/pengertian-windows-dansejarahwindows/, diakses 28 November 2018, 20:39 WIB

[10] STP Administrator, 24 Januari 2016, Definisi Client-Server, Online Pada http://technopark.surakarta.go.id/id/media-publik/komputerteknologi-informasi/188-definisi-client-server, di akses 30 Agustus 2018, 20.26 WIB. 